\title{
Microstructural Analysis of Iron- Chromium-Aluminum Samples Exposed to LOCA-Type Conditions Followed by Quench
}

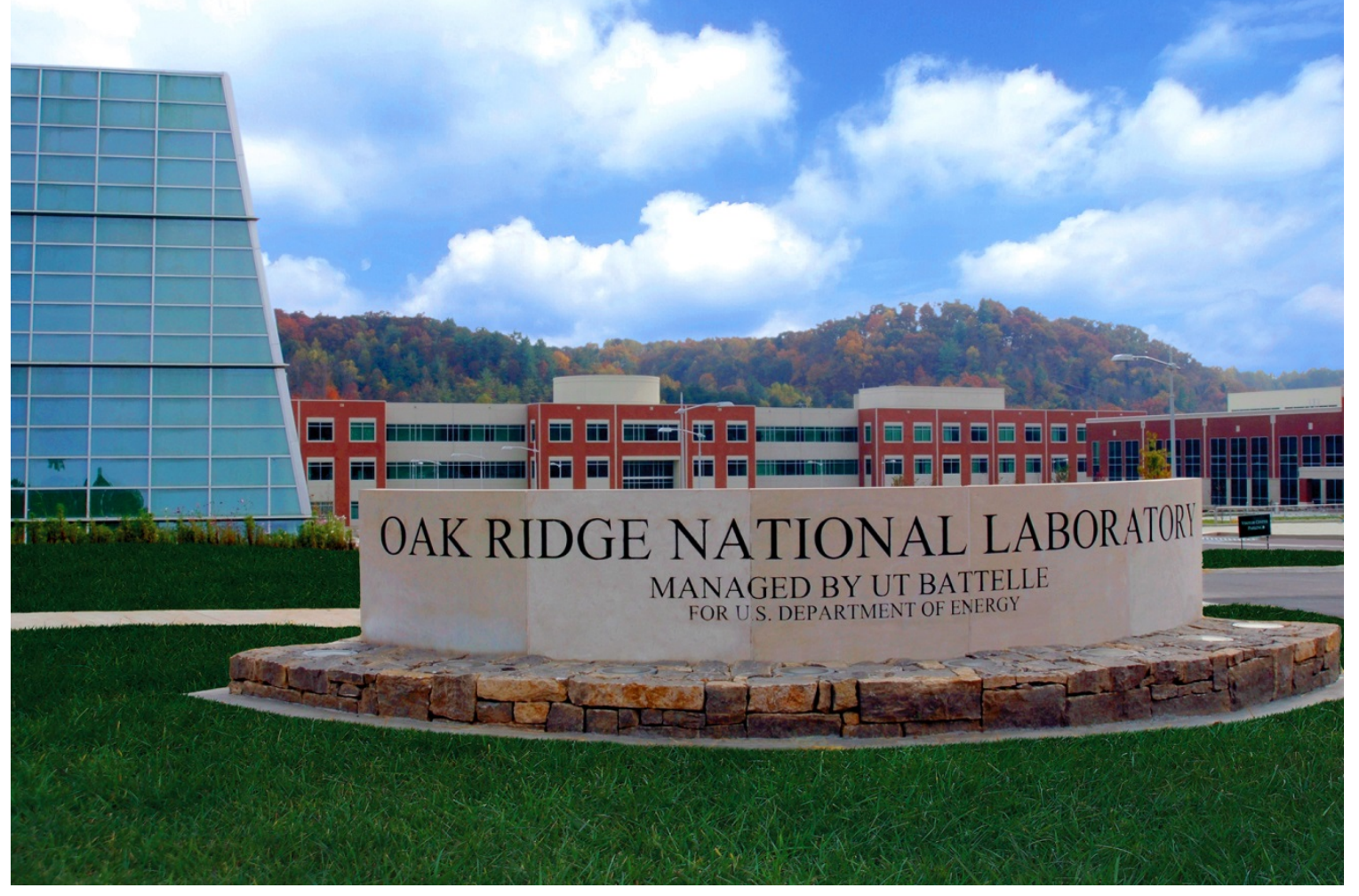

Peter Doyle Andrew Nelson Jason Harp

September 2021 


\title{
DOCUMENT AVAILABILITY
}

Reports produced after January 1, 1996, are generally available free via US Department of Energy (DOE) SciTech Connect.

Website www.osti.gov

Reports produced before January 1, 1996, may be purchased by members of the public from the following source:

\author{
National Technical Information Service \\ 5285 Port Royal Road \\ Springfield, VA 22161 \\ Telephone 703-605-6000 (1-800-553-6847) \\ TDD 703-487-4639 \\ Fax 703-605-6900 \\ E-mail info@ntis.gov \\ Website http://classic.ntis.gov/
}

Reports are available to DOE employees, DOE contractors, Energy Technology Data Exchange representatives, and International Nuclear Information System representatives from the following source:

Office of Scientific and Technical Information

PO Box 62

Oak Ridge, TN 37831

Telephone 865-576-8401

Fax 865-576-5728

E-mail reports@osti.gov

Website https://www.osti.gov/

This report was prepared as an account of work sponsored by an agency of the United States Government. Neither the United States Government nor any agency thereof, nor any of their employees, makes any warranty, express or implied, or assumes any legal liability or responsibility for the accuracy, completeness, or usefulness of any information, apparatus, product, or process disclosed, or represents that its use would not infringe privately owned rights. Reference herein to any specific commercial product, process, or service by trade name, trademark, manufacturer, or otherwise, does not necessarily constitute or imply its endorsement, recommendation, or favoring by the United States Government or any agency thereof. The views and opinions of authors expressed herein do not necessarily state or reflect those of the United States Government or any agency thereof. 
Nuclear Energy and Fuel Cycle Division

\title{
MICROSTRUCTURAL ANALYSIS OF IRON-CHROMIUM-ALUMINUM SAMPLES EXPOSED TO ACCIDENT CONDITIONS FOLLOWED BY QUENCH
}

\author{
Peter Doyle \\ Andrew Nelson \\ Jason Harp
}

September 2021

Prepared by

OAK RIDGE NATIONAL LABORATORY

Oak Ridge, TN 37831-6283

managed by

UT-BATTELLE LLC

for the

US DEPARTMENT OF ENERGY

under contract DE-AC05-00OR22725 



\section{CONTENTS}

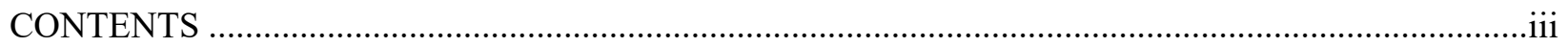

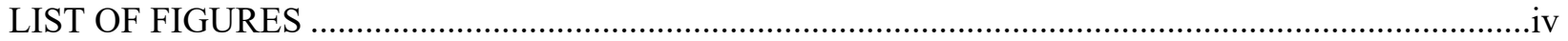

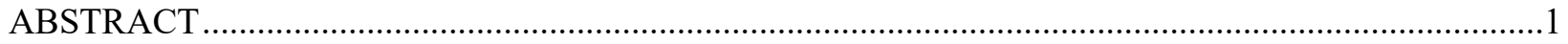

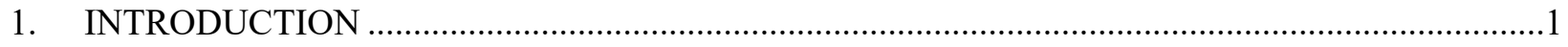

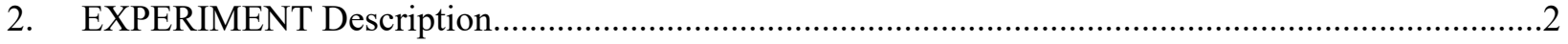

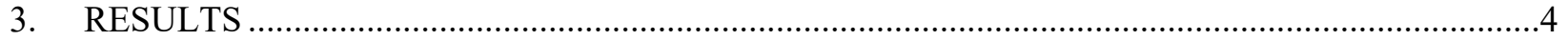

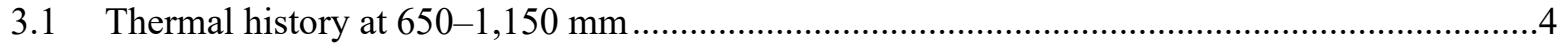

3.2 Microstructure of internal rods across the $750-950 \mathrm{~mm}$ elevations ......................................5

3.3 Microstructure of midrange and external rods across the $750-950 \mathrm{~mm}$ elevation .....................

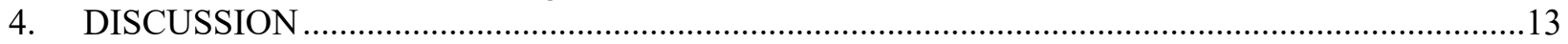

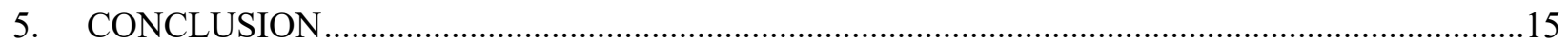

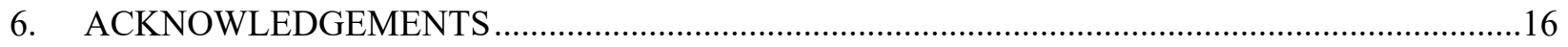

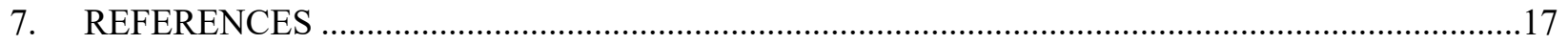




\section{LIST OF FIGURES}

Figure 1. Configuration of rods in the QUENCH-19 experiment......................................................2

Figure 2. Heated rod numbering diagrams at $650,750,850,950,1,050$, and $1,150 \mathrm{~mm}$ elevations. ..........3

Figure 3. Thermocouple readouts from QUENCH-19 across the elevation ranges (a) 650-850 $\mathrm{mm}$, (b) $950 \mathrm{~mm}$, and (c) $1,050-1,150 \mathrm{~mm}$.

Figure 4. Low magnification backscatter electron images of rods 3 (top row) and 4 (bottom row) at 750 (column 1), 850 (column 2), and 950 (column 3) $\mathrm{mm}$.

Figure 5. Low magnification secondary electron (a, c, e) and backscatter electron (b, d, f) images of rods $1(\mathrm{a}, \mathrm{b}), 3(\mathrm{c}, \mathrm{d})$, and $4(\mathrm{e}, \mathrm{f})$ at $750 \mathrm{~mm}$.

Figure 6. Oxide microstructure on segments of rod 3 at $750 \mathrm{~mm}$.

Figure 7. Low magnification secondary $(a, c)$ and backscatter $(b, d)$ electron images of rod 1 (a, b) and $\operatorname{rod} 2(\mathrm{c}, \mathrm{d})$.

Figure 8. Backscatter electron images of internal rod 1 at $950 \mathrm{~mm}$.

Figure 9. Low magnification backscatter electron images of rods 6 (top row) and 8 (bottom row) at 750 (column 1), 850 (column 2), and 950 (column 3) $\mathrm{mm}$.

Figure 10. Backscatter electron images of rods 14 (top row) and 16 (bottom row) at 750 (column 1), 850 (column 2), and 950 (column 3) $\mathrm{mm}$.

Figure 11. Backscatter electron images of the external rods 17, 19, 22, and 23 at $750 \mathrm{~mm}$. .11

Figure 12. Backscatter electron images of the external rods 19, 17, 21, and 22 at $850 \mathrm{~mm}$...................12

Figure 13. Backscatter electron images of the external rods 17, 19, 21, and 23 at $950 \mathrm{~mm}$...................12 


\begin{abstract}
The QUENCH-19 experiment was performed to examine the behavior of FeCrAl-alloy B136Y3 as a potential nuclear fuel cladding under accident conditions. Over the course of the test, a surrogate bundle achieved a temperature of just over $1,400^{\circ} \mathrm{C}$. Post-test characterization revealed that the $\mathrm{FeCrAl}$ formed a thin layer of aluminum oxide that protected most of the underlying cladding and surrogate fuel rods. However, a few rods were heavily corroded and even destroyed, primarily by thermocouple-FeCrAl interactions and by subsequent steam, FeCrAl, and $\mathrm{ZrO}_{2}$ interactions. Absent these effects, it is suggested that $\mathrm{FeCrAl}$ offers improved performance and enhanced accident tolerance under these conditions.
\end{abstract}

\title{
1. INTRODUCTION
}

The QUENCH series of tests was originally designed to test the performance of zirconium-based alloys under accident conditions followed by a rapid water quench ${ }^{1}$. These tests revealed useful information about the release of hydrogen and initial temperature increases as a function of a variety of parameters. As the industry has sought more accident tolerant fuels and associated cladding since the Fukushima-Daiichi accident in 2011, materials such as $\mathrm{SiC}$ and $\mathrm{FeCrAl}$ have gained increasing attention due in part to excellent oxidation properties under accident scenarios ${ }^{2}$. However, as shown in the previous QUENCH tests $^{3}$, when quenching from high temperature, the sudden impact of water onto the hot rods can lead to an initial oxidation of the material that releases energy and hydrogen, causing a temporary temperature spike before additional cold water reduces the temperature and minimizes further oxidation. To understand the thermal and chemical behavior under such accident conditions as well as to determine the microstructural impacts, QUENCH-19 was performed, using an ORNL FeCrAl alloy, B1236Y3. The goal of this work is to evaluate the microstructure of the B136Y3 rods exposed in the QUENCH-19 test. A full description of these test results will be reported separately.

\footnotetext{
${ }^{1}$ Ott and Robb, "Simulation of QUENCH-15 and Preliminary Pre-Test Predictions for QUENCH-19"; Steinbrück et al., "Synopsis and Outcome of the QUENCH Experimental Program"; Stuckert et al., "Results of the Bundle Test QUENCH-19 with FeCrAl Claddings BT - Proceedings of Global/Top Fuel 2019, Seattle, WA, September 22-26, 2019"; Robb, Howell, and Ott, Parametric and Experimentally Informed BWR Severe Accident Analysis Utilizing FeCrAl - (M3FT-17OR020205041); Robb, Mcmurray, and Terrani, "Severe Accident Analysis of BWR Core Fueled with UO2/FeCrAl with Updated Materials and Melt Properties from Experiments"; Haste et al., "A Comparison of Core Degradation Phenomena in the CORA, QUENCH, Phébus SFD and Phébus FP Experiments."

${ }^{2}$ Pint et al., "Material Selection for Accident Tolerant Fuel Cladding"; Pint et al., "High Temperature Oxidation of Fuel Cladding Candidate Materials in Steam-Hydrogen Environments"; Gamble et al., "An Investigation of FeCrAl Cladding Behavior under Normal Operating and Loss of Coolant Conditions"; Massey et al., "Cladding Burst Behavior of Fe-Based Alloys under LOCA"; Pint et al., "Development of ODS FeCrAl for Compatibility in Fusion and Fission Energy Applications"; Terrani, "Accident Tolerant Fuel Cladding Development: Promise, Status, and Challenges."

${ }^{3}$ Steinbrück et al., "Synopsis and Outcome of the QUENCH Experimental Program"; Haste et al., "A Comparison of Core Degradation Phenomena in the CORA, QUENCH, Phébus SFD and Phébus FP Experiments"; Stuckert et al., "Results of Severe Fuel Damage Experiment QUENCH-15 with ZIRLO Cladding Tubes. (KIT Scientific Reports ; 7576)."
} 


\section{EXPERIMENT DESCRIPTION}

Two types of FeCrAl-class rods were tested in QUENCH-19 at Karlsruhe Institute of Technology (KIT), Germany. The first set, $\mathrm{Fe}_{\text {bal }} \mathrm{Cr}_{22} \mathrm{Al}_{5.8} \mathrm{Si}_{0.7} \mathrm{Mn}_{0.4} \mathrm{C}_{0.08}$, corresponded to commercially available Kanthal $\mathrm{FeCrAl}$. Rods of this type were placed in the corners of the test setup and also used as the shroud in the experiment. B136Y3, with a composition of $\mathrm{Fe}_{\mathrm{bal}} \mathrm{Cr}_{13} \mathrm{Al}_{6.2} \mathrm{Y}_{0.03} \mathrm{C}_{0.01}$ and produced at Oak Ridge National Laboratory (ORNL), was the focus of this experiment; it formed the cladding around each of the heated rods in the test with a wall thickness of $0.382 \mathrm{~mm}$ and a diameter of $9.52 \mathrm{~mm}$. The heated rods acted as simulated full fuel rods by using central $5 \mathrm{~mm}$ diameter electric tungsten heating rods, surrounded by $\mathrm{ZrO}_{2}$ annular pellets ( $8.6 \mathrm{~mm}$ outer diameter, $5.2 \mathrm{~mm}$ inner diameter, $11 \mathrm{~mm}$ height) that served to electrically isolate the $\mathrm{W}$ element from the system and to fill the gap between the heater and the cladding inner wall. Twenty-four such rods with B136Y3 cladding were added in a fully symmetric scheme such that there were 4 internal rods, 12 middle rods, and 8 outer rods. Each of these heated rods was pre-filled with krypton to achieve $0.23 \mathrm{MPa}$ internal pressure when the maximum rod temperature was $800 \mathrm{~K}$. Seven Kanthal rods were also added on the corners, similar to QUENCH-15. This configuration is shown in Figure 1. Except for the changes in material and as noted below, the test was designed and operated to be identical to QUENCH-15; published reports on that experiment provide details ${ }^{4}$.

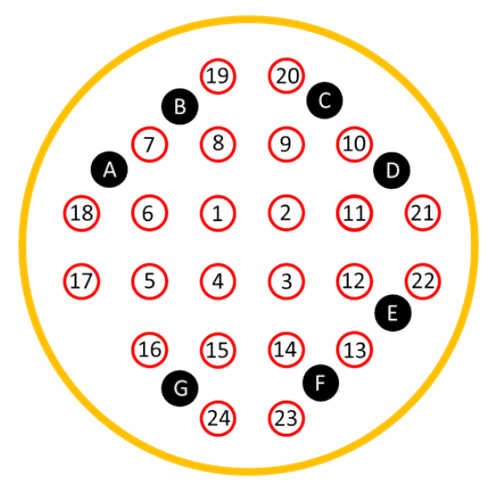

Figure 1. Configuration of rods in the QUENCH-19

experiment. Numbered rods are B136Y3, whereas lettered rods are Kanthal.

Briefly describing some of the details, the test bundle was made $2 \mathrm{~m}$ high with five spacer grids. The central section, heated by tungsten, comprised $1 \mathrm{~m}$ of this length. Molybdenum rods coated by $\mathrm{ZrO}_{2}$ layer heat the colder end sections. Of the spacer grids, the grid closest to the base was an AREVA Inconel spacer grid, located at $-200 \mathrm{~mm}$. (That is, $200 \mathrm{~mm}$ below the start of the section, heated by tungsten. Hereafter, all location designations will be made with the start of the heated section as a reference point.) The other four grids were composed of B136Y3 and placed at 50, 550, 1,050, and 1,410 mm, respectively, above the start of the heated section. In addition, several tungsten-rhenium thermocouples (TC) were sheathed in AISI 304 stainless steel and spot welded onto various locations between 650 and $1,350 \mathrm{~mm}$ on the shroud and heated rods. Rod configurations are shown for $650-1,150 \mathrm{~mm}$ in Figure 2 (the Kanthal rods were omitted in this diagram). Each TC was placed on the respective rod at the point furthest from the center of the assembly. For example, a TC on rod 1 is located such that the wire runs in the channel surrounded by rods $1,6,7$, and 8 . A few of the thermocouples of interest were found during testing to be defective; these are indicated by a diagonal red line on the rod symbol in Figure 2. Some $\mathrm{NiCr} / \mathrm{Ni}$ thermocouples were located in the cooler sections below $650 \mathrm{~mm}$. All thermocouples placed at

${ }^{4}$ Ott and Robb, "Simulation of QUENCH-15 and Preliminary Pre-Test Predictions for QUENCH-19"; Stuckert et al., "Results of Severe Fuel Damage Experiment QUENCH-15 with ZIRLO Cladding Tubes. (KIT Scientific Reports ; 7576)"; Steinbrück et al., "Synopsis and Outcome of the QUENCH Experimental Program." 
and below $850 \mathrm{~mm}$ were inserted at the base of the test bundle, with the remaining thermocouples inserted from the top of the bundle.

Following assembly, the system was heated for $\sim 6,000 \mathrm{~s}$ at $10-13 \mathrm{~kW}$, followed by a rapid heating over $\sim 1,110 \mathrm{~s}$ by varying the power up to $17 \mathrm{~kW}$. Unlike QUENCH-15, the system next was held at $18 \mathrm{~kW}$ for an additional 2,000 s until a rapid quench was induced by adding $48 \mathrm{~g} / \mathrm{s}$ of water over the course of $170 \mathrm{~s}$, bringing the temperature back to near room temperature. Throughout the test, thermocouple data was monitored to track the temperature along the cladding surfaces. Additional details and schematics can be found in Stuckert et al, 20195. After testing, the apparatus was filled with epoxy and cut into sections at various locations. Three such sections, at 750,850 , and $950 \mathrm{~mm}$, were polished and sent to ORNL for examination on a TESCAN MIRA3 scanning electron microscope (SEM) with both secondary electron (SE) and backscatter electron (BSE) imaging. Imaging was conducted at $20 \mathrm{keV}$.
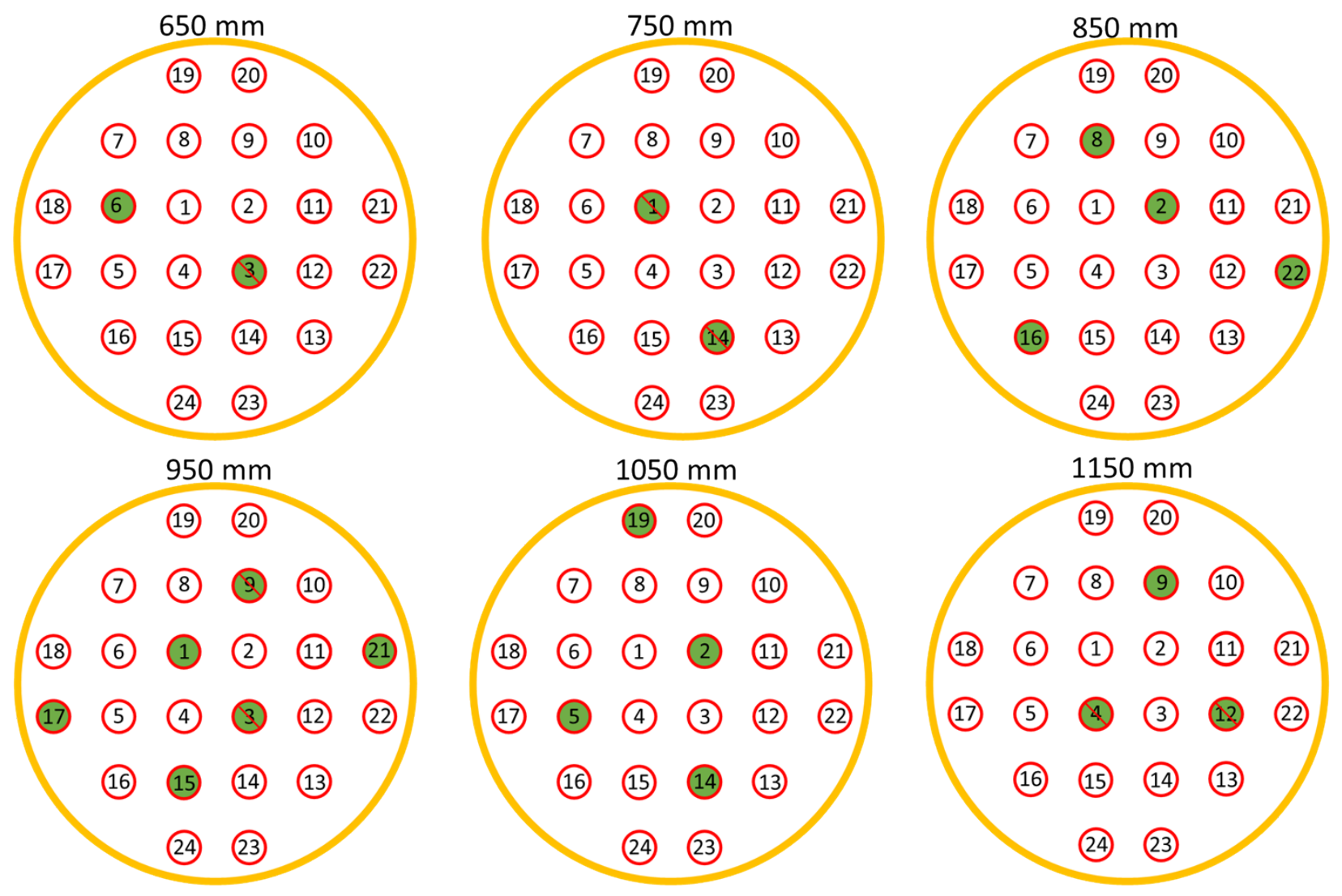

Figure 2. Heated rod numbering diagrams at 650, 750, 850,950, 1,050, and 1,150 $\mathrm{mm}$ elevations. The shroud is displayed as a yellow circle around the exterior of the rod set. Filled green circles represent rods that have thermocouples tacked onto them. All thermocouples were welded onto the rod at the point furthest from the center of the rod assembly. A diagonal red line is overlaid on the rod symbols where the thermocouples were placed, but for which no useful thermocouple data exist because of defects during the test.

\footnotetext{
${ }^{5}$ Stuckert et al., "Results of the Bundle Test QUENCH-19 with FeCrAl Claddings BT - Proceedings of Global/Top Fuel 2019, Seattle, WA, September 22-26, 2019.”
} 


\section{RESULTS}

A full description of the results from this test is beyond the scope of this report. Details concerning comparisons to QUENCH-15, on which QUENCH-19 was modeled, and wholistic reporting of the thermocouple readouts are presented in other published work ${ }^{6}$. This section will cover data related to elevations 750,850 , and $950 \mathrm{~mm}$, for which cross sections have been examined at ORNL.

\subsection{THERMAL HISTORY AT 650-1,150 MM}

During the tests, several thermocouples were defective, and useful data from them is not available. To have the best context for the experiment (and because of thermocouple failures at the regions of interest), a thermal history of the test across the elevations from 650 to $1,150 \mathrm{~mm}$ is shown in Figure 3. The data point of $650 \mathrm{~mm}$ was added to the low-temperature plot (Figure 3a), and the higher elevation data from 1,050 to $1,150 \mathrm{~mm}$ is represented in Figure $3 \mathrm{c}$. The three different heater voltage segments are noted on Figure 3 as pre-oxidation, transient, and hold, respectively, per Section 2.

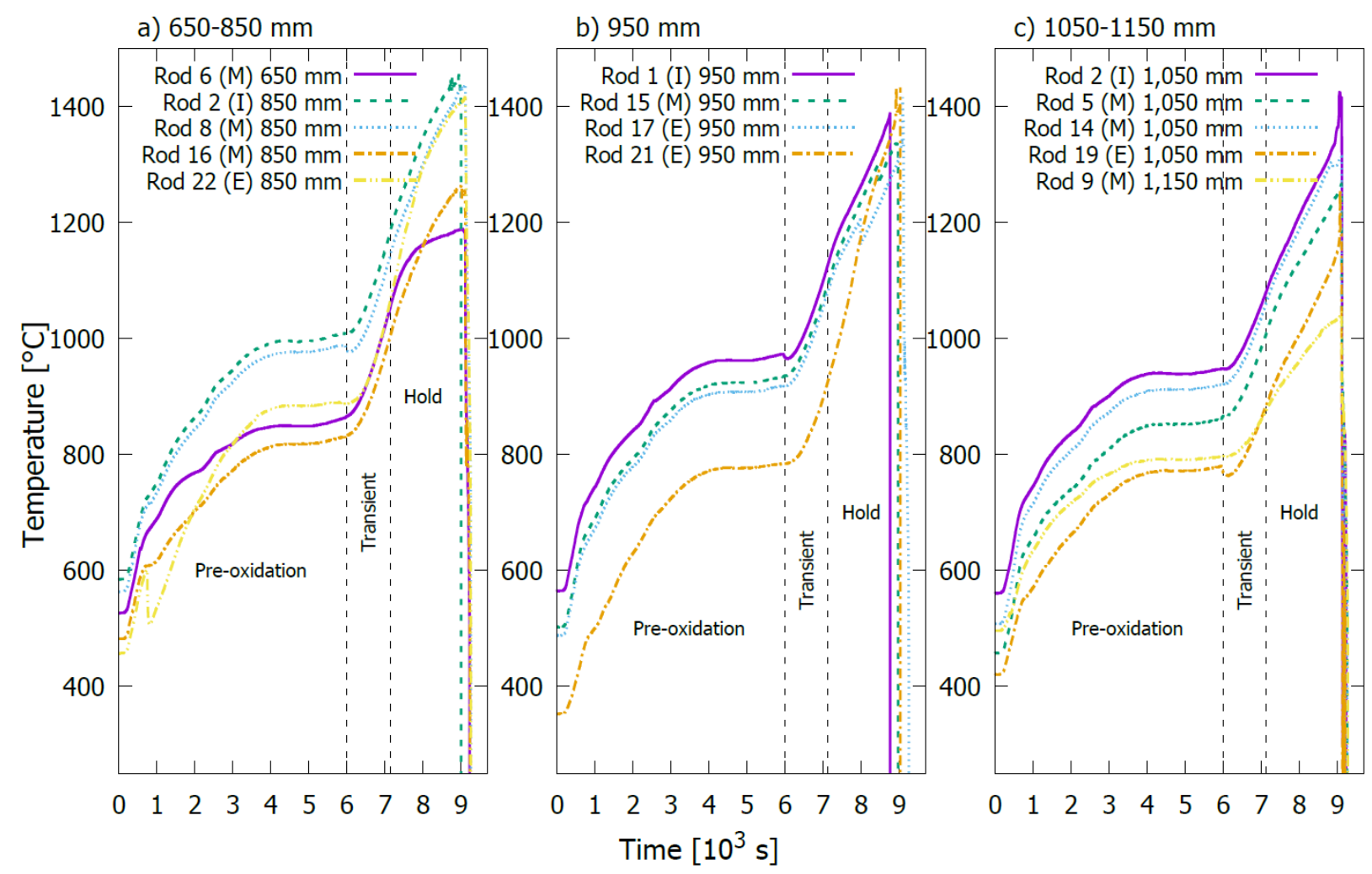

Figure 3. Thermocouple readouts from QUENCH-19 across the elevation ranges (a) $650-850 \mathrm{~mm}$, (b) $950 \mathrm{~mm}$, and (c) 1,050-1,150 mm. Each key entry shows the rod and elevation from which the thermocouple data came, along with a rod locator designation “( $\mathrm{X})$," where X is I, M, or E (standing for one of the internal rods [\#1-4], one of the midrange rods [\#5-16], or one of the exterior rods [\#17-24], respectively). Three ranges — pre-oxidation, transient, and hold—are identified with labels on the plot and separated by dashed vertical lines.

First, comparing the curves in Figure $3 \mathrm{a}$, there is a difference of $200-300^{\circ} \mathrm{C}$ between the midrange rod 6 at $650 \mathrm{~mm}$ and a similarly placed midrange rod 8 at $850 \mathrm{~mm}$. Moreover, the midrange rod 8 at $850 \mathrm{~mm}$

${ }^{6}$ Stuckert et al.; Ott and Robb, "Simulation of QUENCH-15 and Preliminary Pre-Test Predictions for QUENCH19." 
had a temperature profile very similar to that of internal rod 2 . However, rod 16 , which has fewer rods surrounding it than rod 6 , has a temperature profile $100-200^{\circ} \mathrm{C}$ lower than that of rod 6 . Interestingly, rod 22 at $650 \mathrm{~mm}$ has a temperature profile similar to that of rod 16 (albeit somewhat hotter during the transient) until the hold, at which time it achieves the same maximum as rods 2 and 8 at $850 \mathrm{~mm}$. These data at $850 \mathrm{~mm}$ represent the maximum observed temperatures during the test.

Rods 1, 15, and 17, which represent each of the three rod sections (internal, midrange, and external), show surprisingly similar temperature profiles at $950 \mathrm{~mm}$ (Figure 3b). However, the thermocouple on rod 21, which is also external and on the opposite side of the other external rod, 17, reported a temperature consistently $\sim 200^{\circ} \mathrm{C}$ lower than that of the other three rods until the hold time, when the temperature gradually rises to meet the temperature of the rest of the rods.

Above $950 \mathrm{~mm}$, the system cools slightly, and more substantial axial variation is observed. Midrange rods 5 and 14 at $1,050 \mathrm{~mm}$, separated by $90^{\circ}$ rotation, are separated by $50-100^{\circ} \mathrm{C}$ over most of the temperature range, whereas rod 5 was separated only a few degrees from internal rod 2 over the same range. All three rods reached similar maximum temperatures at $950 \mathrm{~mm}$; however, rod 14 does not ever reach that maximum and remains several degrees lower than rods 5 and 2 . In contrast, external rod 19 at $1,050 \mathrm{~mm}$ and midrange rod 9 follow similar, lower-temperature paths with maximum temperatures of just over 1,200 and $1,000^{\circ} \mathrm{C}$, respectively.

Taken together, these data lead to an important conclusion about this test: the axial thermal profile was asymmetric, despite the rod assembly being nearly fully symmetric (see Figure 1, where one Kanthal rod was missing for full symmetry). Given that the Kanthal rods were primarily for instrumentation and did not include a heater, the resistance heating through the tungsten element was fully symmetric throughout the test. As a result, it must be concluded that the asymmetric temperature profiles were caused by asymmetries in the corrosion behavior leading to additional increases in temperature. The following sections offer details on this point.

\subsection{MICROSTRUCTURE OF INTERNAL RODS ACROSS THE 750-950 MM ELEVATIONS}

Figure 4 compares backscatter electron (BSE) images of the full rod cross section for rods 3 (top row) and 4 (bottom row) at 750 (column 1), 850 (column 2), and 950 (column 3) $\mathrm{mm}$. Starting with the lowest elevation, rods 3 and 4 show significantly different microstructures. Rod 4 looks pristine on both the water and $\mathrm{ZrO}_{2}$ sides. In contrast, the $\mathrm{ZrO}_{2}$ side of rod 3 was attacked. In Figure 5 and Figure 6, this defected structure is shown to have two primary components. The one most clearly shown in Figure 6 is the diffusion of the components of at least $\mathrm{Fe}$ into the $\mathrm{ZrO}_{2}$ insulator along with extensive oxide formation at the same location; the second is formation of a thin oxide layer where local attack was not observed. Figure 5a and 5c show significant contrast within the $\mathrm{ZrO}_{2}$ pellet, stemming from the FeCrAl. In particular in Figure 5a and c, the contrasted region appears to be associated with the large internal oxide on the FeCrAl, implying that oxidation of the $\mathrm{FeCrAl}$ may be leading to diffusion between the $\mathrm{ZrO}_{2}$ and $\mathrm{FeCrAl}$. This is confirmed by Figure $6 \mathrm{c}-\mathrm{h}$. Figure $6 \mathrm{c}-\mathrm{d}$ shows the same features as those in Figure 5. In addition Figure $6 \mathrm{f}-\mathrm{h}$ shows small amounts of zirconium diffusing into the FeCrAl cladding and its oxides, whereas Figure 6e shows two features: (1) a thin, dense oxide containing aluminum on the waterside of the cladding; and (2) a thick aluminum-containing oxide on the interior of the coating. In Figure $6 \mathrm{a}-\mathrm{b}$ similar oxidation behavior is observed on both the interior and exterior of the cladding. The internal oxidation behavior of this type is consistent with the other observations of internal oxide formation. Importantly, the presence of a thin external oxide is found at all elevations, implying that the uniform corrosion of $\mathrm{FeCrAl}$ is low compared with localized oxidation, which can be substantial. Therefore, if the localized corrosion effects can be properly accounted for as particular to this experiment, the cladding failures at 850 and $950 \mathrm{~mm}$ may not be observed in a real accident. 
These observations extend to other locations and elevations, beginning in Figure 4. At $850 \mathrm{~mm}$, no damage was found on rod 3, but significant internal and external oxidation is found on rod 4 . Both of these observations are opposite of those at $750 \mathrm{~mm}$. Additionally, the top right of the $850 \mathrm{~mm}$, rod 4 image shows the same oxidation/diffusion behavior that was observed extensively on the interior of rod 3 at $750 \mathrm{~mm}$. Figure 7 shows data from rods 1 and 2 at $850 \mathrm{~mm}$, which supplement the observations from Figure 4. Interestingly, as with rod 3, rod 1 is shown to be undamaged. At $850 \mathrm{~mm}$, none of rods 1, 3, or 4 were originally connected to thermocouples. Rod 2, by contrast, was connected to a thermocouple at 850 $\mathrm{mm}$ and is thoroughly destroyed. The tungsten element was entirely exposed with only a short segment of the $\mathrm{ZrO}_{2}$ washer left behind and the washer was displaced toward the adjacent rod 11. Both the $\mathrm{ZrO}_{2}$ remnant and the residual cladding oxide became extremely porous and were fused together.

Now, looking at $950 \mathrm{~mm}$ in Figure 4, the cladding and $\mathrm{ZrO}_{2}$ for both rods 3 and 4 were fully destroyed; the $\mathrm{ZrO}_{2}$ had partially disappeared and is fully porous. The cladding also fully converted to a porous oxide that is partially fused to the $\mathrm{ZrO}_{2}$ washer. The other two rods were similarly destroyed at $950 \mathrm{~mm}$. The reaction product structure is shown in Figure 8, where on rod 1 the cladding remnants are shown to have fused to the $\mathrm{ZrO}_{2}$ in several places. Moreover, significant diffusion of zirconium into the $\mathrm{FeCrAl}$ oxides and $\mathrm{FeCrAl}$ into the $\mathrm{ZrO}_{2}$ was observed with oxides heterogeneously mixed (Figure 8d-e).
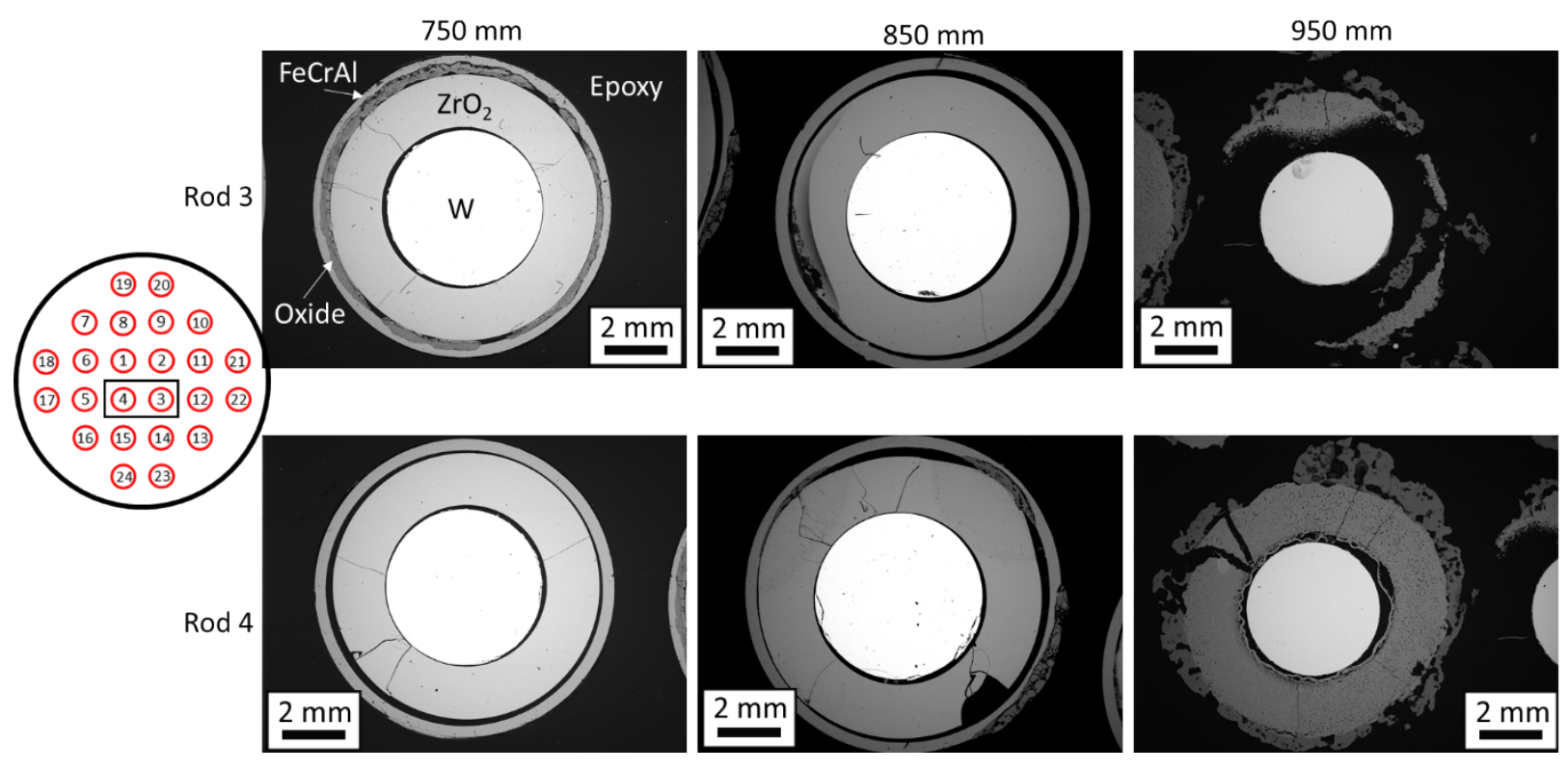

Figure 4. Low magnification backscatter electron images of rods 3 (top row) and 4 (bottom row) at 750 (column 1), 850 (column 2), and 950 (column 3) $\mathrm{mm}$. A rod diagram is shown on the left of the figure with a black box around rods 3 and 4 . 

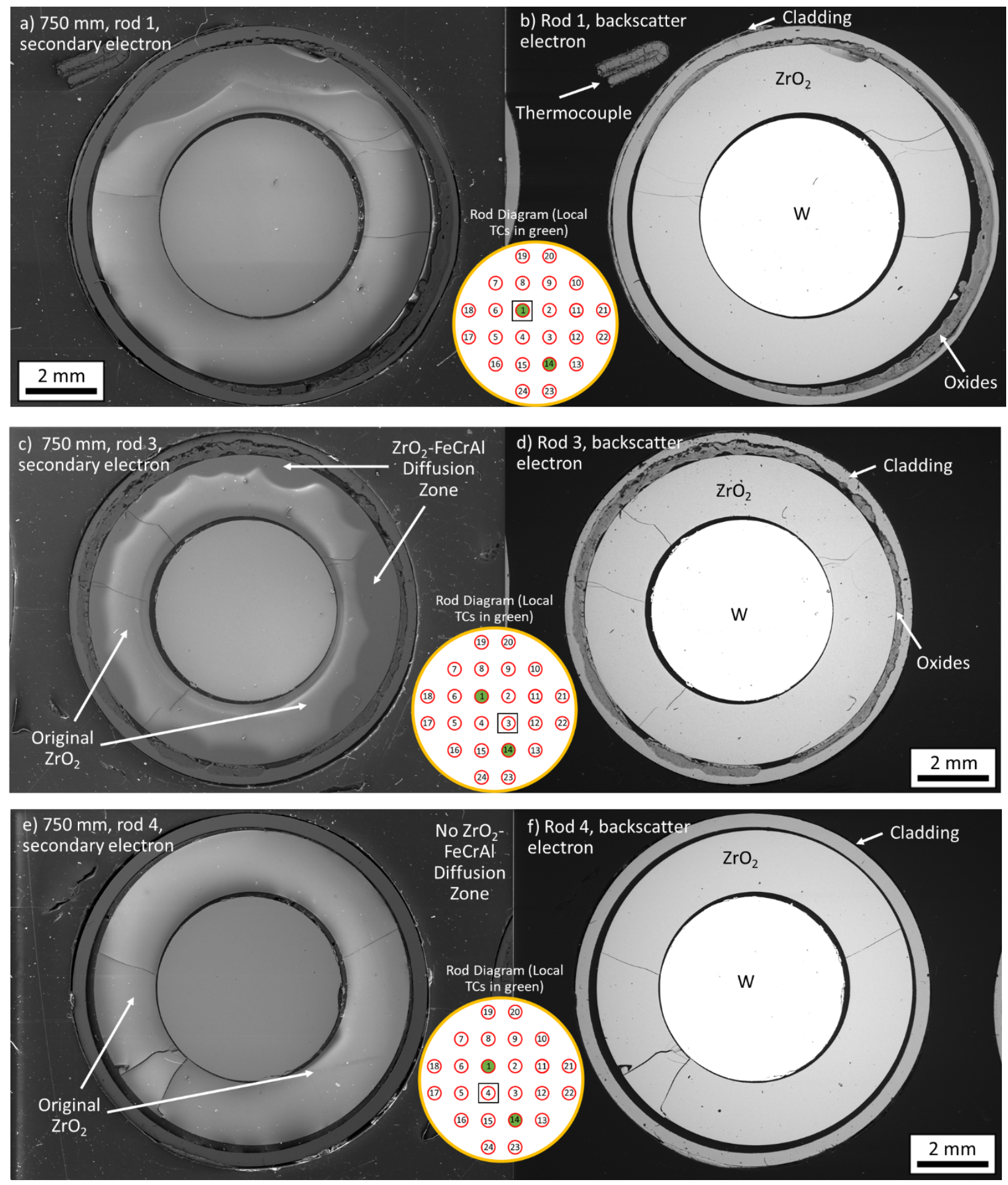

Figure 5. Low magnification secondary electron $(a, c, e)$ and backscatter electron $(b, d, f)$ images of rods $1(\mathbf{a}, \mathbf{b}), \mathbf{3}(\mathbf{c}, \mathbf{d})$, and $4(\mathrm{e}, \mathrm{f})$ at $750 \mathrm{~mm}$. Included with each pair of images is a rod diagram with a box showing the location of the rod. Important features are labeled appropriately. 


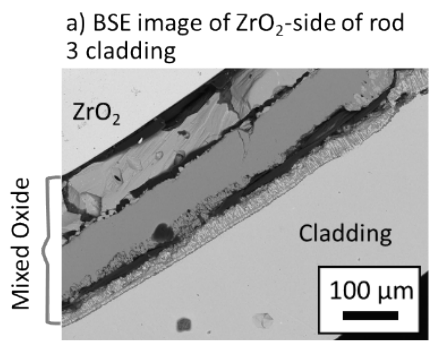

e) Rod 3 O EDS Map of c)

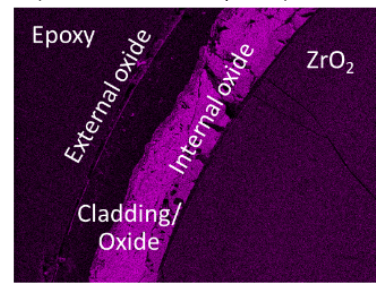

b) BSE image of water-side of rod 3 cladding

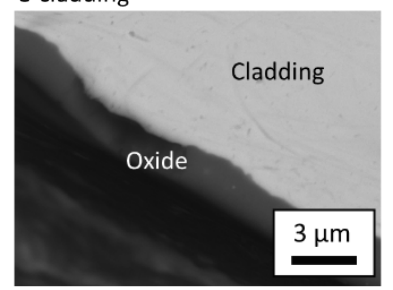

f) Rod 3 Zr EDS Map of c)

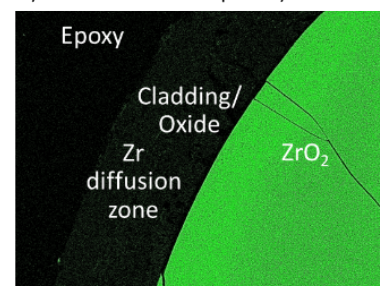

c) SE image of defected area on rod 3

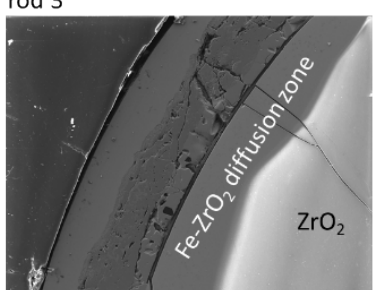

g) Rod 3 Fe EDS Map of c)

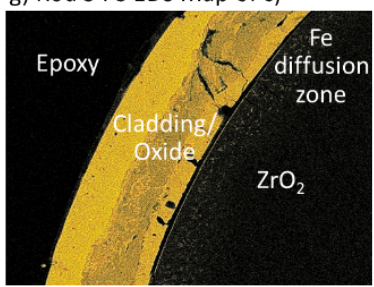

d) BSE image of defected area on $\operatorname{rod} 3$

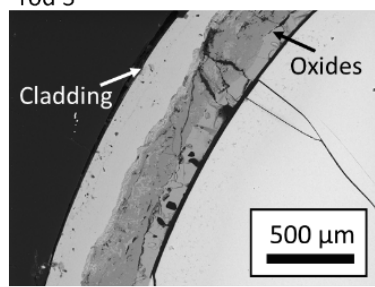

h) Rod 3 Al EDS Map of c)

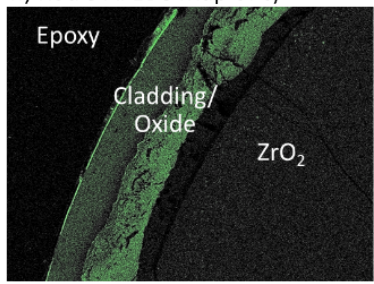

Figure 6. Oxide microstructure on segments of rod 3 at $750 \mathrm{~mm}$. Part (a) shows a backscatter electron (BSE) image of the $\mathrm{ZrO}_{2}$ side of the cladding, revealing a multicomponent oxide. In (b) a BSE image of water-side of the rod 3 cladding shows a single component thin oxide. Parts (c) and (b) show secondary electron (SE) and BSE images, respectively, of a defected cladding region. Parts (e)-(h) show the energy dispersive spectroscopy (EDS) maps of $\mathrm{O}, \mathrm{Zr}, \mathrm{Fe}$, and $\mathrm{Al}$, respectively, of the region in (c) and (d).
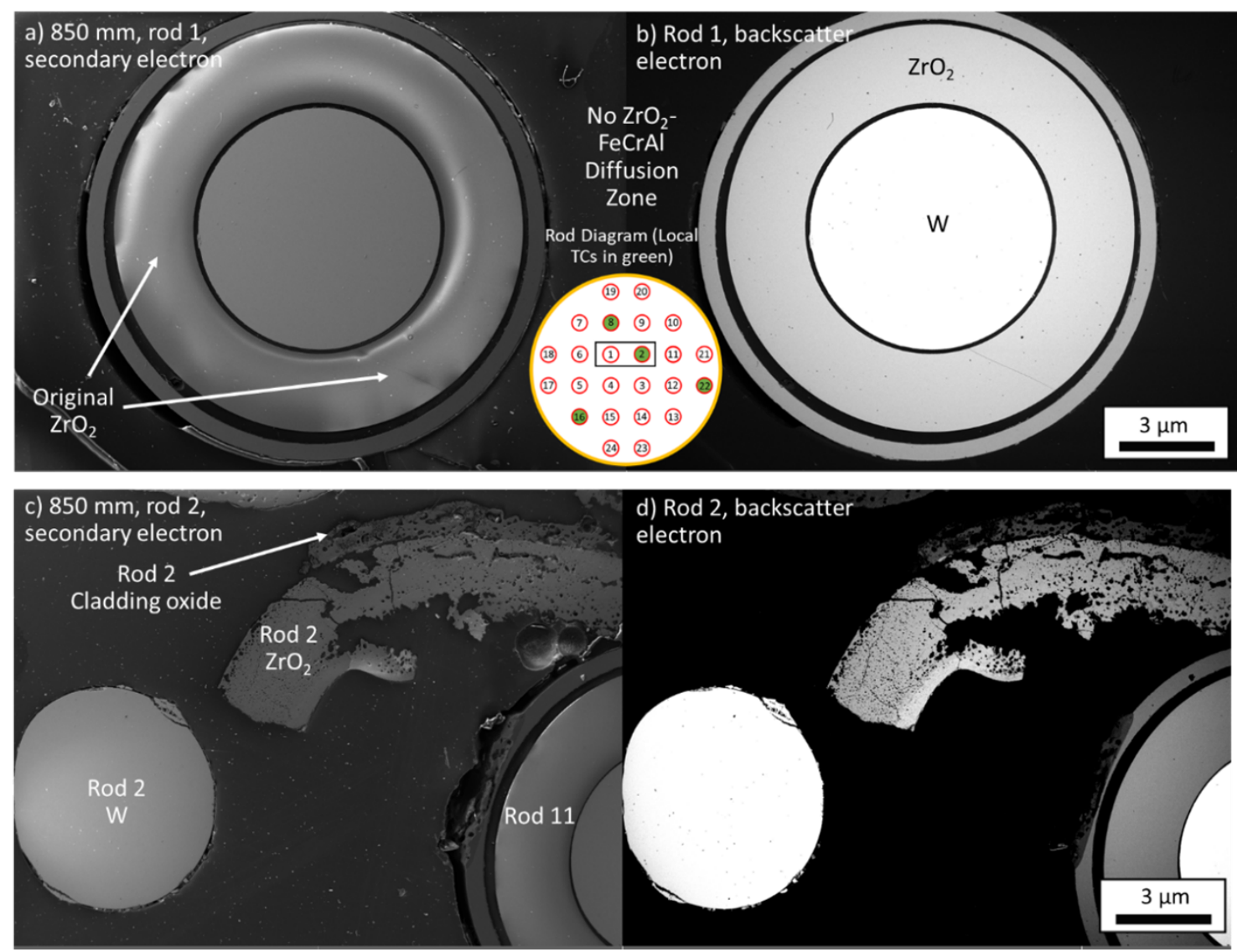

Figure 7. Low magnification secondary $(a, c)$ and backscatter $(b, d)$ electron images of rod 1 (a, b) and rod 2 (c, d). In (c) and (d), the rod was fully destroyed. The previous components of the rod are labeled, as is the adjacent midrange rod 11. 
a) Cladding oxide $/ \mathrm{ZrO}_{2}$ interface

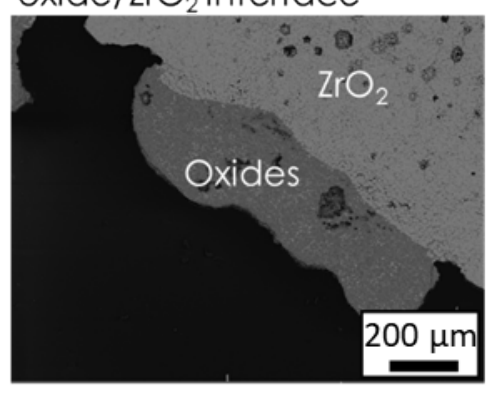

b) Porous fused area at $\mathrm{ZrO}_{2} /$ cladding interface

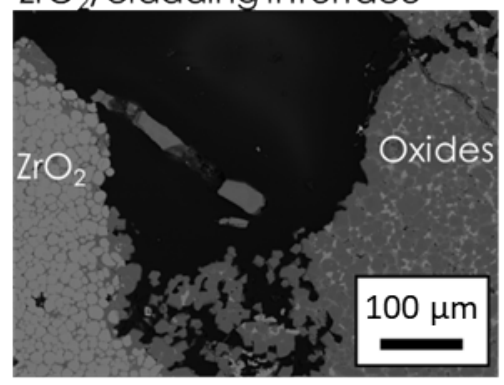

d) Cladding side of $\mathrm{ZrO}_{2} /$ clad interface

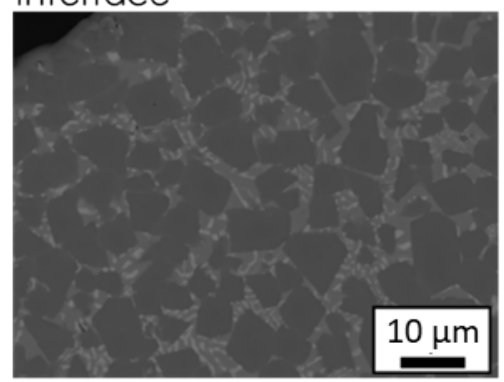

c) Higher magnification of b)

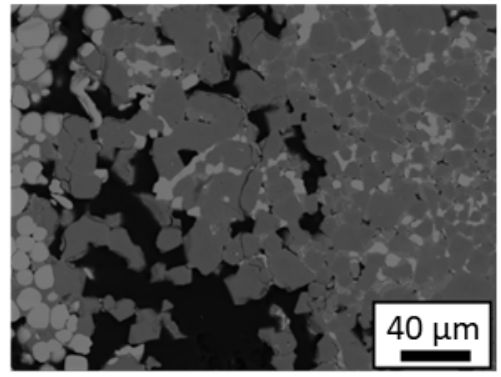

e) Higher magnification of d)

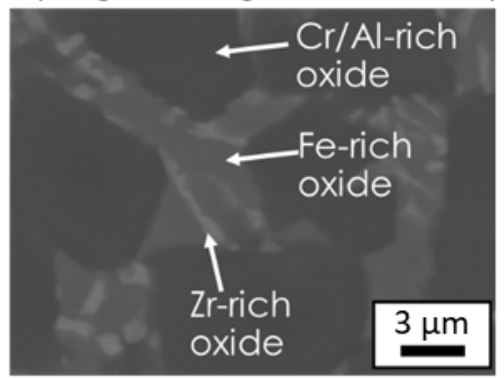

Figure 8. Backscatter electron images of internal rod 1 at $950 \mathrm{~mm}$. Part (a) shows a low magnification image of the cladding $/ \mathrm{ZrO}_{2}$ interface, (b) and (c) show higher magnification images of a different region of fused interface, and (d) and (e) show further magnification of the cladding side of the interface.

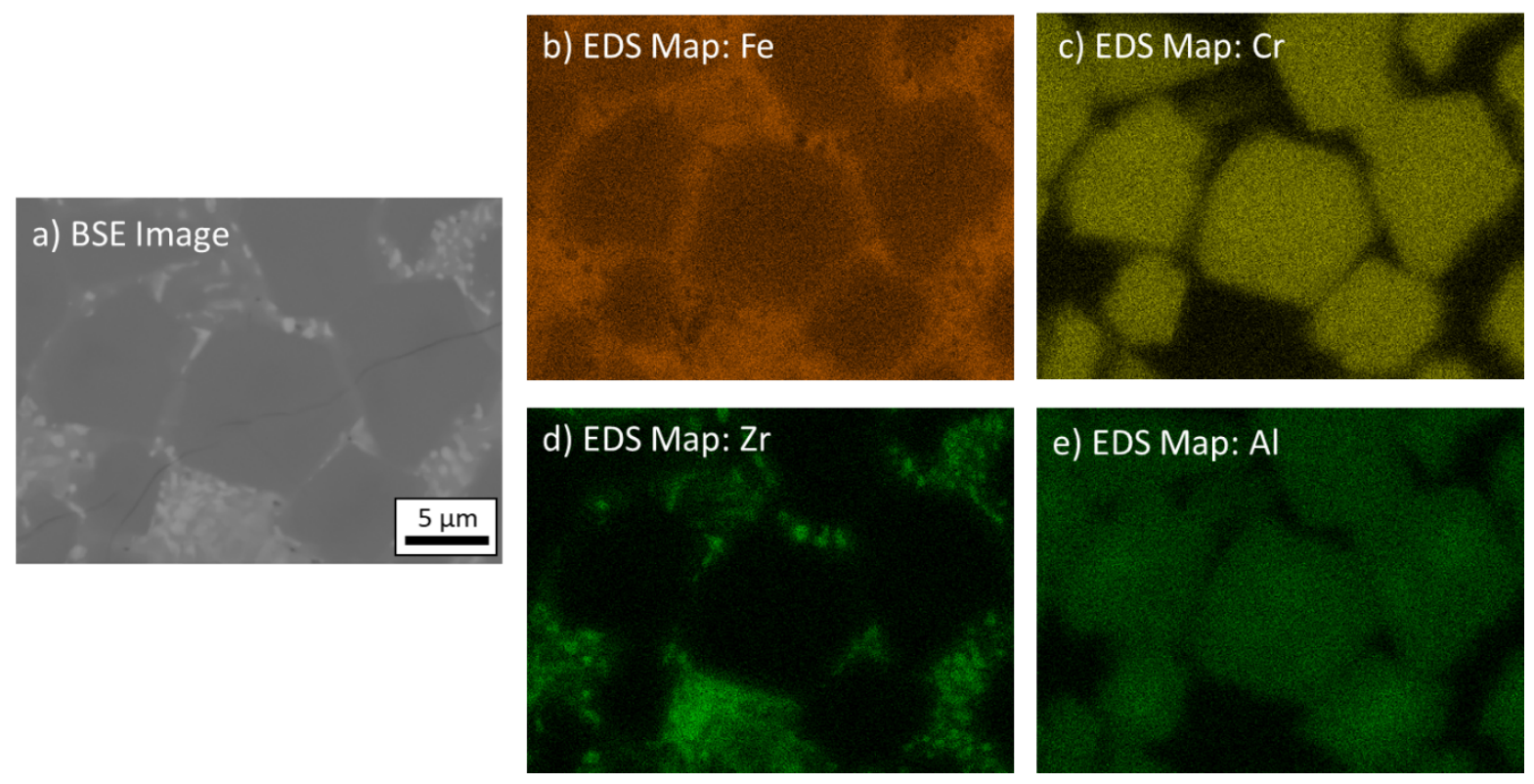

Figure 9: a) Backscatter electron images of internal rod 1 at $950 \mathrm{~mm}$. b)-e) show elemental EDS maps of $\mathrm{Fe}, \mathrm{Cr}, \mathrm{Zr}$, and $\mathrm{Al}$, respectively of the image in a). 


\subsection{MICROSTRUCTURE OF MIDRANGE AND EXTERNAL RODS ACROSS THE 750-950 MM ELEVATION}

The structure of damage and oxide films on the midrange and exterior rods is quite similar to that of the interior rods. Broadly, intact rods and regions of rods had a thin (a few microns thick) oxide film on the cladding exterior. Where the cladding was not intact, either partially or fully, the same type of oxide microstructure was observed, as in Figure 6 and Figure 8, with no notable differences. As such, only the lower magnification images are shown here, and they reveal the important features of the cladding behavior.

Starting with intermediate rods 6 and 8, Figure 10 shows entirely undamaged rods at $750 \mathrm{~mm}$. Despite the presence of a thermocouple (at rod 1) at $750 \mathrm{~mm}$, neither rod shows corresponding damage. At $850 \mathrm{~mm}$, the eutectic behavior begins to operate. Rod 6, which had no thermocouples on or around it, was entirely undamaged. Rod 8 , having a thermocouple welded to it at $850 \mathrm{~mm}$, behaved quite differently. Over half of the rod and cladding remained fully intact, but there was an interaction region near the thermocouple connection point, which led to an attack of both the thermocouple sheath and $\mathrm{FeCrAl} / \mathrm{ZrO}$ on the rod. This behavior is replicated at $950 \mathrm{~mm}$, where a thermocouple on rod 1 appears to have interacted with rods 1 and 6 , as illustrated by the $\sim 3 / 4$ of rod 6 which is intact, whereas the remaining $\sim 1 / 4$ of the rod near the thermocouple was destroyed. On rod 8, about half of the rod is intact and the other half has been destroyed. On either side of rod 8 at $950 \mathrm{~mm}$, rods 1 and 9 were both connected to thermocouples, which may have contributed to the extensive attack on rod 8. Rods 14 and 16 show less extensive damage at all levels, although there was extensive damage on rod 14 at $950 \mathrm{~mm}$ (Figure 11).

External rod images are shown in Figure 12-Figure 14. At $750 \mathrm{~mm}$ (Figure 12), all four of the exterior rods are shown to be perfectly intact, including rod 22 (Figure 12c), which passes right next to a thermocouple wire. By contrast, at $850 \mathrm{~mm}$ (Figure 13), three of the four rods show extensive damage. In Figure 13a, chemical attack of rod 19 is shown by the thermocouple wire for the thermocouple attached to rod 8 at $950 \mathrm{~mm}$. Outside of the attack region around the thermocouple wire, the cladding on rod 19 was fully intact. Rod 17 (Figure 13b), which only has thermocouples above at $950 \mathrm{~mm}$ and on adjacent rod 16 at $850 \mathrm{~mm}$, showed no damage. Rods 21 and 22 at $850 \mathrm{~mm}$ (Figure 13c-d) were both heavily damaged. Rod 21 is damaged only in the direction of rod 22, where both the $\mathrm{ZrO}_{2}$ and cladding in that direction were destroyed. The remainder of rod 21 was fully intact with no significant oxidation. Rod 22's cladding was entirely destroyed. The only cladding remnant was on the right-most portion of the $\mathrm{ZrO}_{2}$, where fully oxidized cladding was fused to the $\mathrm{ZrO}_{2}$.

Finally, the observations at $950 \mathrm{~mm}$ (Figure 14) are broadly similar to the observations at $850 \mathrm{~mm}$. Rod 17 (Figure 14a) appears to have lost its cladding, but there is no evidence of the chemical attack of $\mathrm{ZrO}_{2}$ that was present in other locations. It is possible that the cladding was partially broken during postexperiment processing. In fact, some intact cladding can be observed visually to be under the surface of the clear epoxy. It is thus thought that the lack of cladding on rod 17 at $950 \mathrm{~mm}$ should be considered an artifact of the experiment, not an indication of quench-related failure. By contrast, rod 19 (Figure 14b) was significantly attacked on the $\mathrm{ZrO}_{2}$ and $\mathrm{FeCrAl}$ toward the bottom of the image (facing the assembly center), whereas the top of the image shows intact cladding. There were no attachments at $950 \mathrm{~mm}$, but substantial damage related to thermocouple-cladding interaction was noted at $850 \mathrm{~mm}$ on rod 19 (Figure 13). Rod 21, which was attached to a thermocouple at $950 \mathrm{~mm}$, was fully stripped of its cladding with only some remnants remaining. Rod 23 (Figure 14d), which had no damage below and thermocouple attachments above and below it, was not observed to be damaged in any way. 

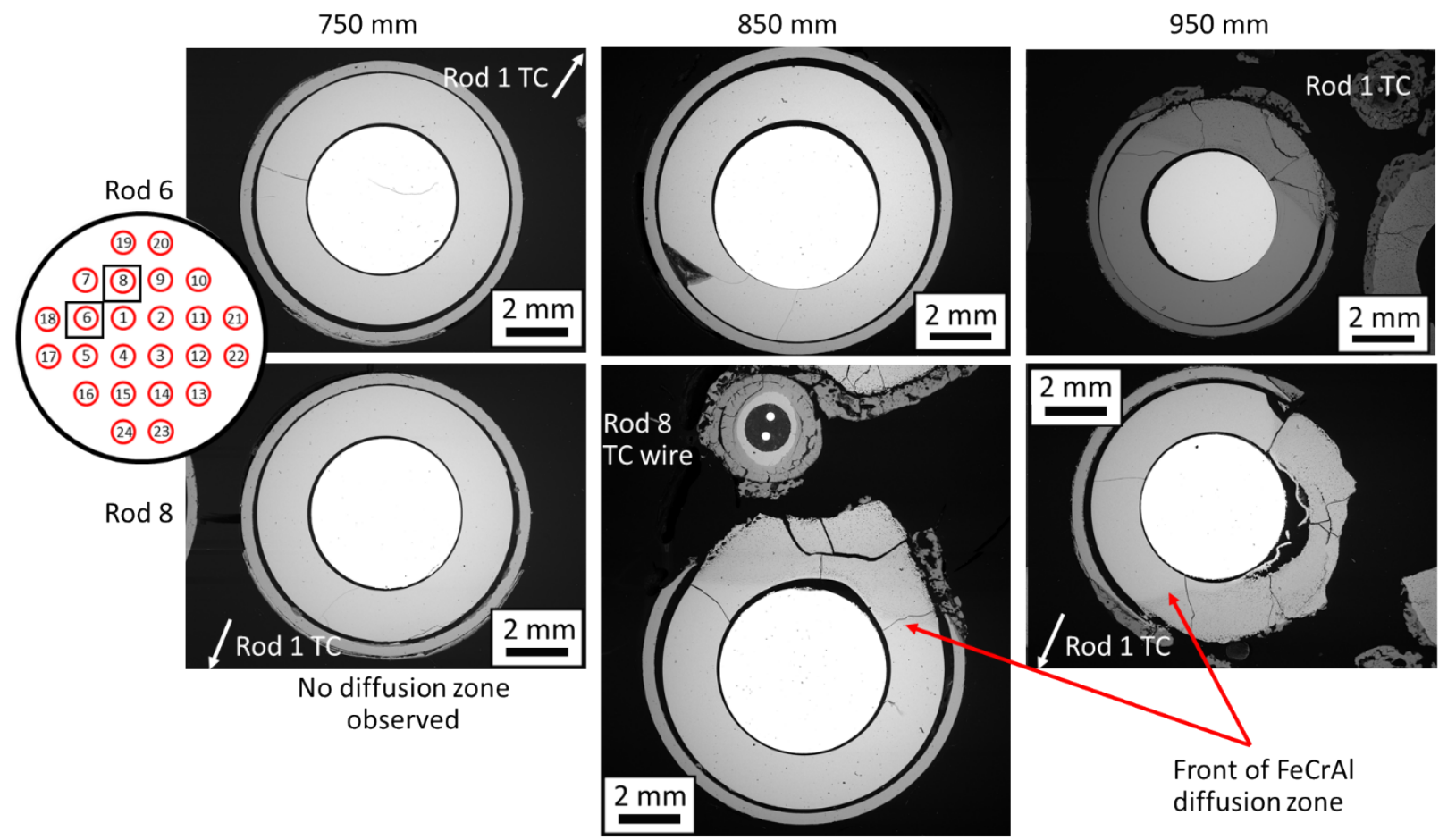

Figure 10. Low magnification backscatter electron images of rods 6 (top row) and 8 (bottom row) at 750 (column 1), 850 (column 2), and 950 (column 3) $\mathbf{m m}$. A rod diagram is shown on the left of the figure with a black box around rods 6 and 8 .
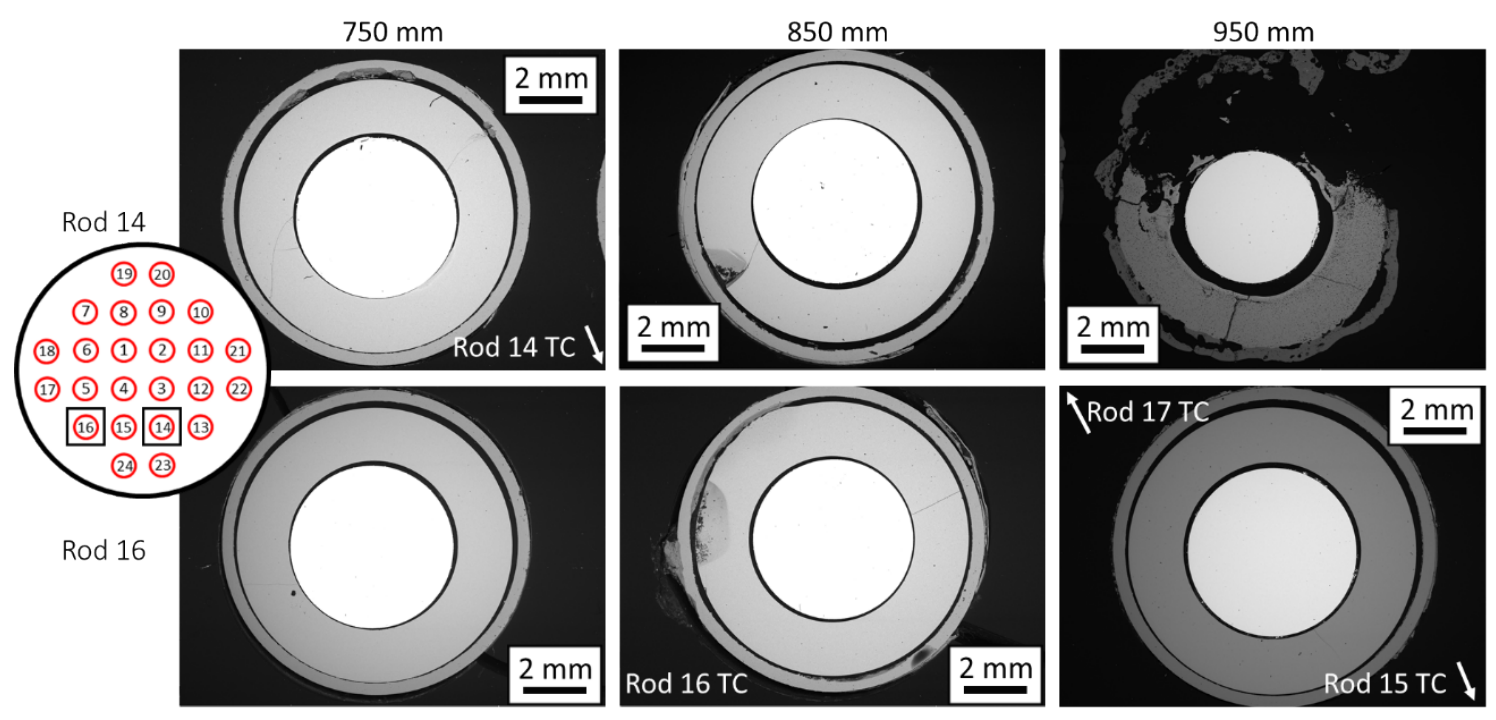

Figure 11. Backscatter electron images of rods 14 (top row) and 16 (bottom row) at 750 (column 1), 850 (column 2), and 950 (column 3) $\mathbf{~ m m}$. A rod diagram is shown on the left of the figure with a black box around rods 14 and 16. 

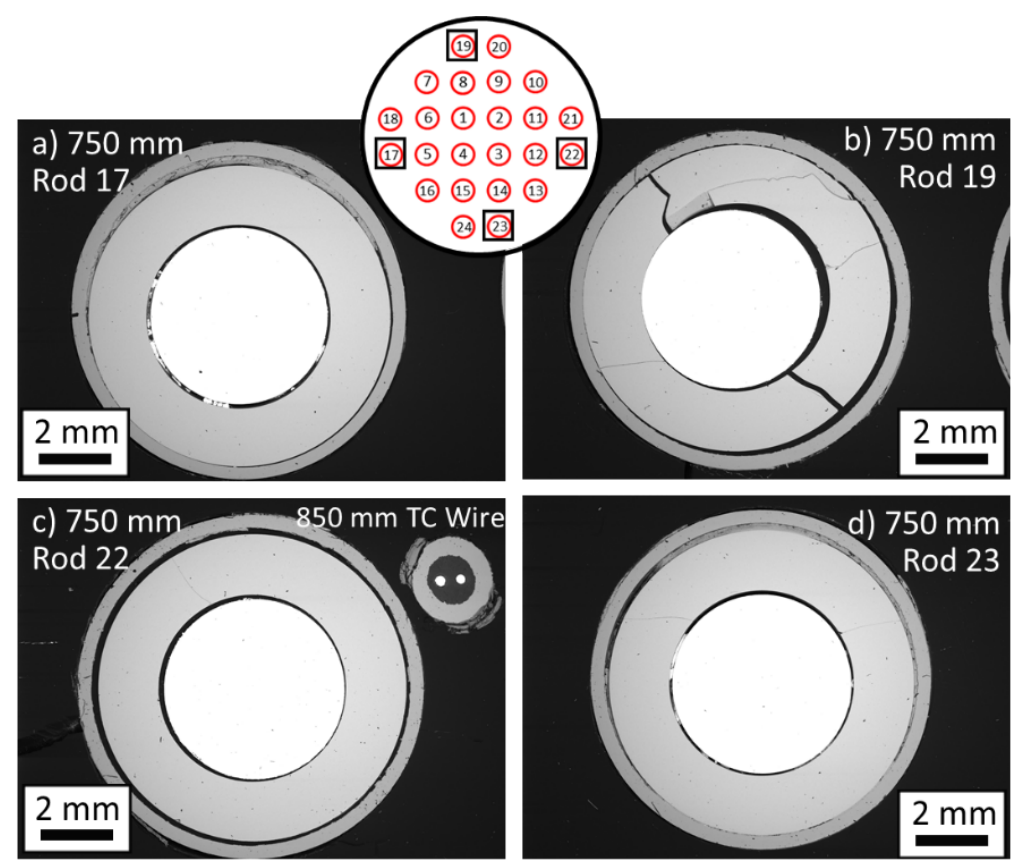

Figure 12. Backscatter electron images of the external rods 17, 19, 22, and 23 at $750 \mathrm{~mm}$. A rod diagram is provided at the top of the figure along with black boxes showing the location of each of the rods in this figure.

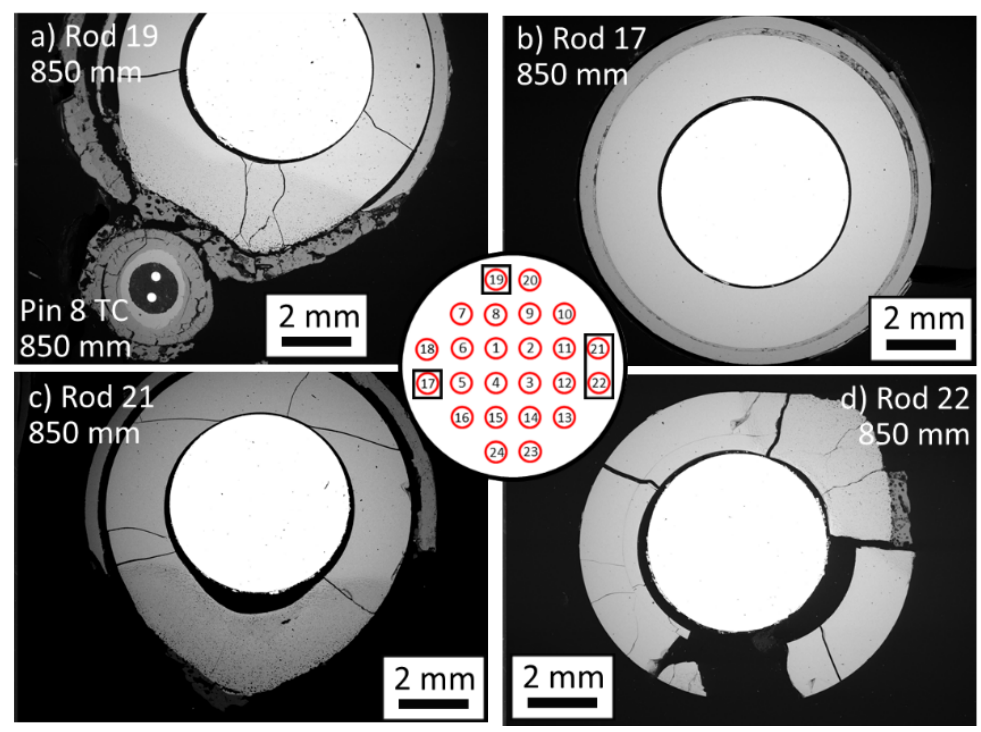

Figure 13. Backscatter electron images of the external rods 19, 17, 21, and 22 at $850 \mathrm{~mm}$. A rod diagram is provided at the top of the figure along with black boxes showing the location of each of the rods in this figure. 

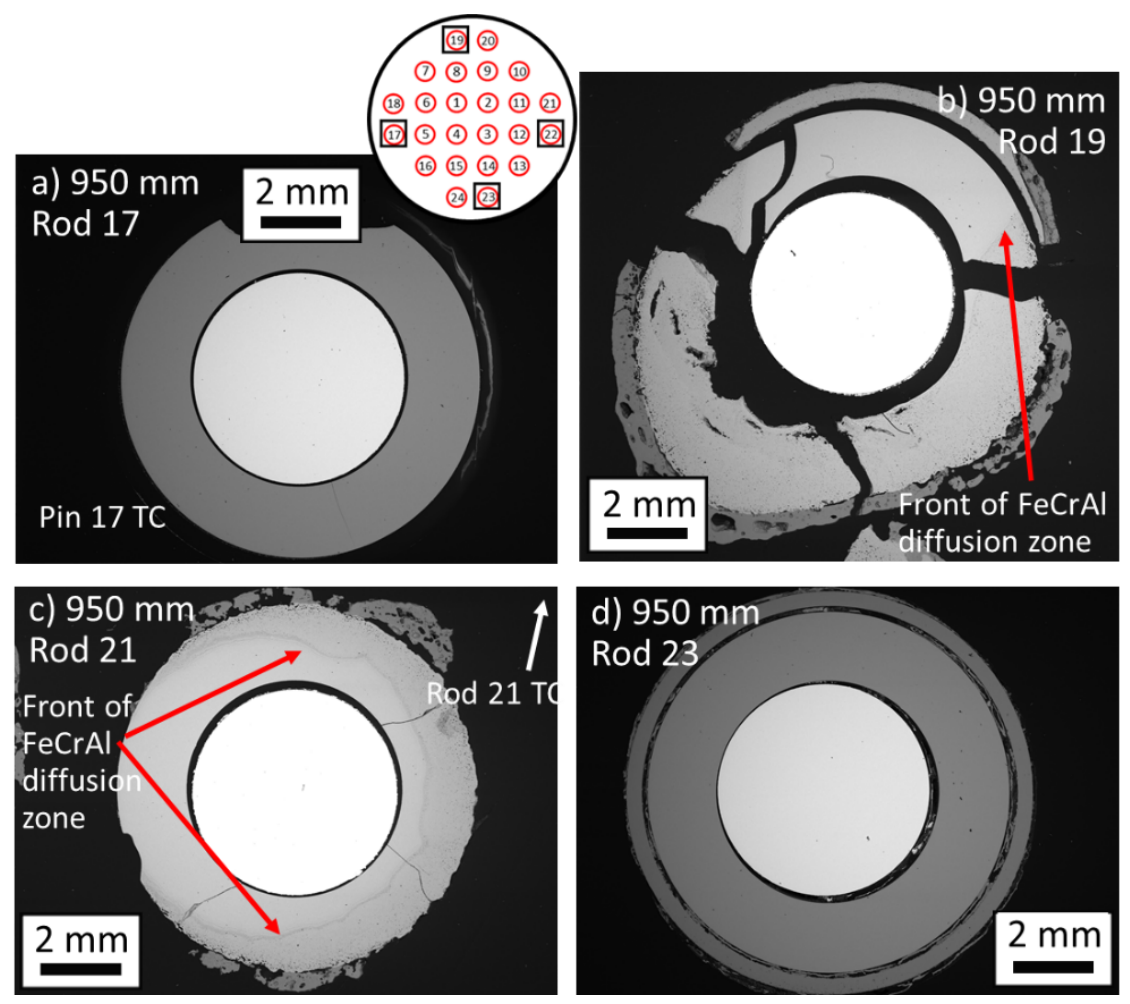

Figure 14. Backscatter electron images of the external rods 17, 19, 21, and 23 at $950 \mathrm{~mm}$. A rod diagram is provided at the top of the figure along with black boxes showing the location of each of the rods in this figure. 


\section{DISCUSSION}

The preceding figures, taken together, reveal a few important points about this system. The first is that without localized effects, the uniform attack of the FeCrAl cladding is extremely small, implying that FeCrAl may be resilient to accidents of this type as long as local attack can be controlled. Secondly, local attack takes on two forms: (a) interaction between thermocouples and cladding and (b) chemical attack of the $\mathrm{ZrO}_{2}$ and $\mathrm{FeCrAl}$ following exposure of the interface to steam.

On the first point, starting with Figure 3, we can safely conclude that the temperature at $750 \mathrm{~mm}$ is within the range of the $650 \mathrm{~mm}$ thermocouple data (rod 6) and the $850 \mathrm{~mm}$ data set. Thus, the maximum temperature at $750 \mathrm{~mm}$ was probably between 1,200 and $1,400^{\circ} \mathrm{C}$. In addition, two defective thermocouples were placed at $750 \mathrm{~mm}$, but there was little evidence to suggest thermocouple-cladding interaction. Some indication of attack is found at Figure 5a, where the edge of the thermocouple on rod 1 was originally attacked. Evidence of internal oxidation and diffusion of metal into the $\mathrm{ZrO}_{2}$ is shown near the location of the thermocouple attachment (Figure 5a). This may be related to thermocouple-induced defects in the cladding slightly below or above the cross-section point. However, comparing the damage in Figure 5a to that of other areas that are clearly related to thermocouple interaction (e.g., Figure 13a), if the damage in Figure 5a is related to thermocouple attack, the attack is minimal. Indeed, across all rods at $750 \mathrm{~mm}$, there was minimal-to-no cladding attack, and all the rods showed a thin $(2-3 \mu \mathrm{m})$ oxide on the exterior of the cladding. Similarly, at $850 \mathrm{~mm}$, whereas thermocouple-cladding interactions became significant, the same thin oxide was observed in all areas that were not locally attacked.

Now turning to thermocouple-cladding interactions, the results show clearly that the most damage in this study was observed at $950 \mathrm{~mm}$ (see especially Figure 4 and Figure 7). Given that the temperature is slightly higher at $850 \mathrm{~mm}$ than at $950 \mathrm{~mm}$ (Figure 3), this behavior cannot be explained by enhanced oxidation rates. The destruction on rod 2 is best understood as caused by eutectic formation between the thermocouple and cladding followed by rapid local oxidation (Figure 2). This process would expose the $\mathrm{ZrO}_{2}$ and $\mathrm{FeCrAl}$ to steam, which catalyzes the oxidation of $\mathrm{FeCrAl}$ and the diffusion of metals into the $\mathrm{ZrO}_{2}$. This can locally destroy both the cladding and zirconia, allowing steam ingress to the internal cladding directly above and below the ingress point, leading to the oxidation/diffusion attack at the cladding $/ \mathrm{ZrO}_{2}$ interface. Because the steam flow is upward, the most significant internal cladding attack would occur at elevations above the eutectic formation point.

Figure 7, Figure 10, and Figure 13 show that each of the locations where significant destruction of the cladding occurred was related to placed thermocouples. However, it is interesting to note that at rod 16 and $850 \mathrm{~mm}$ (Figure 11), the rod shows no sign of localized attack, despite having had a thermocouple attached right at that location. This can be explained by Figure 3a, in which the rod 16 thermocouple at $850 \mathrm{~mm}$ reported a temperature that did not exceed $1,270^{\circ} \mathrm{C}$; it is safe to conclude that the thermocouplecladding interaction reaction requires a temperature above this value to proceed over this time frame.

Considering the data at $950 \mathrm{~mm}$ from this perspective, it becomes clearer as to why the amount of destruction was so high. Of the six thermocouples placed at $950 \mathrm{~mm}$, two were defective and all but one of the other four failed during the actual quench, potentially allowing them to contact more rods. This explanation is offered at least in the case of rod 14 (Figure 11); the top portion of the cross section was destroyed, and rod 3 was attached to a defective thermocouple. Whatever the extent of detachment from that rod, all four of the internal rods were destroyed. Given that rods 1 and 3 had been welded to thermocouples, the destruction on these two fits with the proposed explanation. Considering also that the thermocouple on rod 2 at $850 \mathrm{~mm}$ seems to have led to destruction of the cladding at that location, downstream destruction of the rod 2 cladding at $950 \mathrm{~mm}$ is also reasonable. This leaves only rod 4, which had no thermocouples near it, to explain. There was one thermocouple at $1,150 \mathrm{~mm}$, but upstream effects, 
especially over that distance, are not expected and would be inconsistent with other observations, such as with rod 3, which showed no corrosion at $850 \mathrm{~mm}$ despite showing extensive damage at $950 \mathrm{~mm}$.

In fact, the $950 \mathrm{~mm}$, rod 4 data is not fully explicable from the data found in this work. As always, it is possible that there were defects in the cladding at the start of the test that allowed ingress at the $950 \mathrm{~mm}$ location and subsequent failure. It is evident there was already some attack at $850 \mathrm{~mm}$, both internal and external (Figure 4). However, rod 4 is not the only rod where damage is not fully related to thermocouple placement. At $750 \mathrm{~mm}$ on rod 3, there was extensive internal attack and no external attack (besides the thin oxide film). In fact, it is suggested that these few examples can be properly explained by initial cladding defects and tube rupture. Recall that these rods were pressurized to $0.23 \mathrm{MPa}$ (at $800 \mathrm{~K}$ ). On rupture, some pieces of the cladding can relocate, as shown for rod 2 and $850 \mathrm{~mm}$, potentially with enough force that if said pieces were to hit a defected portion of the cladding, the interior could be exposed to attack. Alternatively, simply heating up to temperature may have been significant enough to cause rod whole failures that were not connected to the surrounding rod behavior.

Regardless, whether the cladding is penetrated by eutectic formation or some other means, once it is opened, a second mechanism kicks in that leads to the extensively observed attack that moves well beyond the eutectic region. As steam attacks the internal side of the cladding, the cladding begins to contact the $\mathrm{ZrO}_{2}$. Next, FeCrAl and $\mathrm{ZrO}_{2}$ begin to interact together, leading to fusion of the cladding oxides with the $\mathrm{ZrO}_{2}$ and diffusion of components of both phases into each other.

This proposal is both encouraging and concerning for the viability of FeCrAl under these conditions. First, $\mathrm{ZrO}_{2}$ and thermocouples will not be present in an actual reactor and with pure FeCrAl rods. Without thermocouples (or if the thermocouple sheaths had also been constructed of the B136Y material), the data from this test imply that nearly all failure would have been absent from this test and $\mathrm{FeCrAl}$ would have maintained a protective aluminum oxide in most areas. For the remaining failures - caused by mechanical damage, manufacturing defects, and the like - it is possible that in a real reactor, the reactions in the system containing steam, $\mathrm{FeCrAl}$, and fuel will be lower than for the system containing steam, FeCrAl, and $\mathrm{ZrO}_{2}$. However, the opposite is also possible. Figure 8 in particular reveals the presence of significant heterogeneity in the mixed oxide region. Because a precise, $\mathrm{ZrO}_{2}$-specific mechanism has not been identified in this work, there is no reason to expect the $\mathrm{UO}_{2}$ system will not behave similarly. Moreover, fuel fragment implantation into the interior cladding wall will somewhat alter the cladding chemistry on the immediate interior; the effects of this implantation on internal rod oxidation are not clear at this time. Each of these items deserves serious consideration, and additional work is warranted. 


\section{CONCLUSION}

QUENCH-19 was the latest test performed in the series of QUENCH tests initially designed for the purpose of understanding how quenching a reactor from high temperatures affects the materials and hydrogen release rates of zirconium-based alloys. This test was designed to be similar to QUENCH-15, with a longer hold time after the transient. The samples were examined after exposure to understand their microstructure at three different elevations representing the peak temperatures in the test.

Electron microscopy revealed the following features. At the lowest elevation $(750 \mathrm{~mm}$, between 1,200 and $1,400^{\circ} \mathrm{C}$ ), little rod damage was observed, and there was no destruction of cladding or formation of 2-3 $\mu \mathrm{m}$ alumina scales on the exterior of all the cladding. However, where rod damage was found, it originated inside the cladding and involved interaction between the $\mathrm{ZrO}_{2}$ and $\mathrm{FeCrAl}$. This behavior was attributed to steam ingress through defects in the cladding. The two higher elevations had similar maximum temperatures above $1,400^{\circ} \mathrm{C}$, with $850 \mathrm{~mm}$ the hottest elevation and the $950 \mathrm{~mm}$ elevation slightly cooler. In addition to a stable external oxide, significant attack of the FeCrAl was observed in the vicinity of welded thermocouples. This damage was often catastrophic, leading to full loss of cladding. In some places it also led to the loss of the underlying $\mathrm{ZrO}_{2}$. It is suggested that in the absence of the thermocouple-cladding interactions, FeCrAl cladding is likely to remain intact and provide enhanced accident tolerance. 


\section{ACKNOWLEDGEMENTS}

The authors would like to acknowledge the staff at KIT, in particular Juri Stuckert, Martin Steinbrück, and Mirco Große, for their excellent work in running this experiment and providing extensive data sets and the examined samples to us. Further, we would like to acknowledge Kurt Terrani for his work in conceiving this test. The work was supported by the Advanced Fuels Campaign of the US DOE Office of Nuclear Energy. 


\section{REFERENCES}

Gamble, K A, T Barani, D Pizzocri, J D Hales, K A Terrani, and G Pastore. "An Investigation of FeCrAl Cladding Behavior under Normal Operating and Loss of Coolant Conditions." Journal of Nuclear Materials 491 (2017): 55-66. https://doi.org/https://doi.org/10.1016/j.jnucmat.2017.04.039.

Haste, T., M. Steinbrück, M. Barrachin, O. De Luze, M. Grosse, and J. Stuckert. "A Comparison of Core Degradation Phenomena in the CORA, QUENCH, Phébus SFD and Phébus FP Experiments." Nuclear Engineering and Design 283 (2015): 8-20. https://doi.org/10.1016/j.nucengdes.2014.06.035.

Massey, Caleb P, Kurt A Terrani, Sebastien N Dryepondt, and Bruce A Rodt. "Cladding Burst Behavior of Fe-Based Alloys under LOCA.” Journal of Nuclear Materials 470 (2016): 128-38. https://doi.org/https://doi.org/10.1016/j.jnucmat.2015.12.018.

Ott, L J, and K R Robb. "Simulation of QUENCH-15 and Preliminary Pre-Test Predictions for QUENCH-19.” Ornl/Spr-2018/832. Oak Ridge, TN, 2018.

Rodt, B A, S Dryepondt, K A Unocic, and D T Hoelzer. "Development of ODS FeCrAl for Compatibility in Fusion and Fission Energy Applications." JOM 66, no. 12 (2014): 2458-66. https://doi.org/10.1007/s11837-014-1200-z.

Rodt, B A, K A Terrani, M P Brady, T Cheng, and J R Keiser. "High Temperature Oxidation of Fuel Cladding Candidate Materials in Steam-Hydrogen Environments." Journal of Nuclear Materials 440, no. 1 (2013): 420-27. https://doi.org/https://doi.org/10.1016/j.jnucmat.2013.05.047.

Rodt, B A, K A Terrani, Y Yamamoto, and L L Snead. "Material Selection for Accident Tolerant Fuel Cladding." Metallurgical and Materials Transactions E 2, no. 3 (2015): 190-96. https://doi.org/10.1007/s40553-015-0056-7.

Robb, K R, J W Mcmurray, and K A Terrani. "Severe Accident Analysis of BWR Core Fueled with UO2/FeCrAl with Updated Materials and Melt Properties from Experiments," 2016.

Robb, Kevin R, Michael Howell, and Larry J Ott. Parametric and Experimentally Informed BWR Severe Accident Analysis Utilizing FeCrAl - (M3FT-17OR020205041), 2017. https://www.osti.gov/servlets/purl/1399971.

Steinbrück, M., M. Große, L. Sepold, and J. Stuckert. "Synopsis and Outcome of the QUENCH Experimental Program.” Nuclear Engineering and Design 240, no. 7 (2010): 1714-27. https://doi.org/10.1016/j.nucengdes.2010.03.021.

Stuckert, J, M Große, U Stegmaier, and M Steinbrück. "Results of Severe Fuel Damage Experiment QUENCH-15 with ZIRLO Cladding Tubes. (KIT Scientific Reports ; 7576),” 2011. https://doi.org/10.5445/KSP/1000022788.

Stuckert, Juri, Mirco Grosse, Martin Steinbrueck, and Kurt Terrani. "Results of the Bundle Test QUENCH-19 with FeCrAl Claddings BT - Proceedings of Global/Top Fuel 2019, Seattle, WA, September 22-26, 2019,” 922-27. Seattle, WA, USA: American Nuclear Society, 2019.

Terrani, Kurt A. "Accident Tolerant Fuel Cladding Development: Promise, Status, and Challenges." Journal of Nuclear Materials 501 (2018): 13-30. 
https://doi.org/https://doi.org/10.1016/j.jnucmat.2017.12.043. 